\title{
Designing of Guided Discovery Learning on a Paramagnetic Heat Engine as an Enrichment Material
}

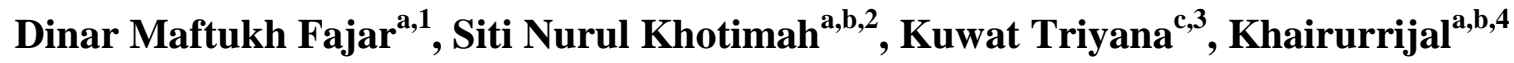 \\ ${ }^{\mathrm{a}}$ Master Program in Physics Teaching, Faculty of Mathematics and Natural Sciences, Institut Teknologi Bandung, \\ Jalan Ganesa 10, Bandung 40132, Indonesia \\ ${ }^{\mathrm{b}}$ Department of Physics, Faculty of Mathematics and Natural Sciences, Institut Teknologi Bandung, \\ Jalan Ganesa 10, Bandung 40132, Indonesia \\ ${ }^{\mathrm{c}}$ Department of Physics, Faculty of Mathematics and Natural Sciences, Gadjah Mada University, \\ Sekip Utara BLS 21, Yogyakarta 55281, Indonesia \\ 11dinarmaftukh@students.itb.ac.id, ${ }^{2}$ nurul@ fi.itb.ac.id, ${ }^{3}$ triyana@gmail.com, ${ }^{4}$ krijal@ fi.itb.ac.id
}

\begin{abstract}
A heat engine that works under the Carnot cycle can be created by employing a paramagnetic material. The topic of paramagnetic heat engine is not included in the Indonesian senior high school physics curriculum. However, it can be categorized as an enrichment material of physics since it describes a broad application of the Carnot cycle. Teaching using the guided discovery learning approach is known to give improvements of students' reasoning and creativity. This paper describes a design on how a paramagnetic heat engine is taught by the guided discovery learning approach. The stages are described in the following sequences: (1) Students begin the lesson by asking questions about other applications of the Carnot cycle that are not explained in the textbook; (2) A teacher gives clues that a heat engine can be created by employing a paramagnetic material; (3) Students investigate what quantities that enable paramagnetic substances can be used as a material for a heat engine; (4) Under the guidance of a teacher, students derive mathematical equations for designing paramagnetic heat engine; and (5) Students make conclusions and generalizations about activities that have been done. In addition, in each stage, an assessment is wrapped-up by the teacher to evaluate the students' reasoning and creativity to gain understanding in a meaningful and constructive manner.
\end{abstract}

Keywords: Carnot cycle, enrichment material, guided discovery learning, paramagnetic heat engine.

\section{Introduction}

A number of educational studies suggest that teaching methods in accordance with the constructivist approach, in which students learn more effectively by constructing their own knowledge, should be applied in science teaching design. One of these methods is guided discovery learning. Discovery is a way from the unknown to the known by the learners themselves. Bruner (1966) states that learning happens by discovery, prioritizes reflection, thinking, experimenting, and exploring [1]. In learning science, students begin with observing phenomena from daily life, propose hypotheses, test them like scientists, and meanwhile, gain advanced level cognitive skills [2]. The roles of a teacher are conditioning suitable learning environment, exciting students about classroom materials, and posing sequences of question that direct them to the learning goals [3]. Without teacher's guidance, students' discovering activity diverges from intended goals [4]. Therefore, discovery learning under teacher's guidance gives effective impact for students in gaining knowledge in constructive manners.

The guided discovery learning method has more benefits compared to the traditional one. As mentioned above, in the guided discovery learning, students are active. Learning is not defined as simply absorbing what they read from textbook or listen from teacher's explanation, but they seek new knowledge actively, in such like hands-on activity [5]. The focus of learning is process-oriented, not just finding the correct answer from rote memorization. Moreover, failure in discovery learning is seen as positive circumstance since it teaches students experiences and responsibilities in conducting the process. A teacher will give feedback to all students' achievement. Students' learning is enhanced, deepened, and made more permanent by discussion on the topic with other learners [3]. While in the traditional one, learning is teacher-centered so that it does not stimulate students to be autonomous.

This paper describes a design of physics learning by applying the guided discovery method to teach an enrichment material. Note that an enrichment material might be said to involve: staying with a theme, subject or skill and developing it in depth; 'rounding out' the basic curriculum subjects with a wider context; relating learning to new areas; and/or providing students with experiences outside the 'regular' curriculum [6]. It gives students opportunities for accelerated progress and access to new, more challenging concepts or content, etc [7]. Based on the definition, we consider that a topic on thermodynamics is potential in creating a unique learning material. Referring to Indonesian Senior High School physics curriculum of Kurikulum 2013 about thermodynamics, we developed an enrichment material entitled "paramagnetic heat engine". It was motivated after reading a textbook that explains the analogy of ideal gas with other substances that meet the laws of thermodynamics [8].

\section{Methodology}

Learning design is an inevitable fundamental thing in a teaching-learning process. In practice, it adheres to teacher's professional tasks, such as: setting teaching session, 
composing learning material, planning classroom activity, and setting assessment [9]. Moreover, it is the most commonly used term to describe the systematic development associated with learning theories as a better understanding of the process involved to support teachers' practices in guaranteeing the quality of learning. However, it should be noted that the term is not without controversy and overlaps to some extent with other terms, such as instructional design, curriculum design and course design [10].

In creating a learning design, a teacher should consider the following main factors: (1) Learning objectives, (2) Learning analysis, (3) Learner, (4) Learning strategy, and (5) Assessment. Since the material presented in this paper is an enrichment, those considerations become very important for establishing the suitability of contents, goals, and method of learning $[11,12]$.

Design of guided discovery learning is set by considering its main goal, that is to stimulate students work and think independently but directed on target. A teacher needs to measure the degree of guidance given to students reflectively. This way will discern it from pure discovery and direct instruction. Pure discovery is not suggested by many studies since it likely generates misconceptions from unregulated students' thinking result [4]. While direct instruction is more suitable for fixed or procedural topics that students learn by adopting directly what teacher instruct. Such way cannot be applied an enrichment material since it is less black and white and needs teacher to be flexible in making judgements in a wide variety of situations.

Five aspects previously presented should be considered in making a learning design. Guided discovery learning will work best when well designed. When poorly designed and facilitated, it will seem pointless, perhaps even manipulative.

\section{Results and Discussion}

The following is explanation about some factors in creating a design of guided discovery learning on paramagnetic heat engine. Analysis was derived from existing curriculum, physics reference, students' characteristic, and some relevant educational studies. This is 'minimal' consideration; some points may have deeper explanation based on local condition.

\section{Learning objectives}

An enrichment material must obey the existing curriculum [12]. This is worth underlining to avoid teacher's ambitions to teach all new materials to students, whereas they definitely may not match to the curriculum [13]. The learning objectives must refer to the physics curriculum of Kurikulum 2013 that is detailed by core and basic competences. There are two relevant basic competences related to the topic of paramagnetic heat engine, that is: (1) Describing the laws of thermodynamics and their applications in technology, (2) Analyzing the ideal gas state by applying the laws of thermodynamics [14].

In addition to present a wider and/or deeper content, an enrichment material is known effective in enhancing students' thinking skill, such as problem solving, creative thinking, and reasoning [15]. Furthermore, it promises to reach the highest cognitive level. Noting that learning succeeds when students reached the evaluation level as given by Bloom's taxonomy [16], the thermodynamics enrichment material can bring students to reach the evaluation cognitive level if students can compare and create a heat engine with other relevant materials, such as a paramagnetic substance as shown in Table 1. The table also depicts cognitive levels of learning objectives on thermodynamics targeted by a teacher. Therefore, in order to reach the evaluation level, students must fulfill the lower cognitive levels. The enrichment material is taught when the main one has been mastered by students by the common teaching-learning activity.

Table 1 Bloom's taxonomy on thermodynamics learning.

\begin{tabular}{|c|c|c|}
\hline $\begin{array}{l}\text { Learning } \\
\text { Objective }\end{array}$ & $\begin{array}{c}\text { Practical Example in } \\
\text { Thermodynamics Lesson }\end{array}$ & Material \\
\hline Knowledge & $\begin{array}{l}\text { Stating the general equation of } \\
\text { ideal gas }\end{array}$ & \multirow{4}{*}{ Main } \\
\hline Comprehension & $\begin{array}{l}\text { Explaining the process of } \\
\text { isobaric, isothermal, isochoric, } \\
\text { and adiabatic in ideal gas }\end{array}$ & \\
\hline Application & $\begin{array}{l}\text { Calculating internal energy, } \\
\text { work, and heat of each } \\
\text { thermodynamic process }\end{array}$ & \\
\hline Analysis & $\begin{array}{l}\text { Analyze the diagram of Carnot } \\
\text { engine }\end{array}$ & \\
\hline Synthesis & $\begin{array}{l}\text { Plan Carnot engine with } \\
\text { combining its existing quantities }\end{array}$ & \multirow[b]{2}{*}{ Enrichmen } \\
\hline Evaluation & $\begin{array}{l}\text { Comparing a heat engine with } \\
\text { ideal gas to that with } \\
\text { paramagnetic substance obeying } \\
\text { Curie's law }\end{array}$ & \\
\hline
\end{tabular}

\section{Learning Analysis}

This part is a process to analyzing topics or contents learned in classroom activities, including learning sources used by students to probe information. Here a teacher prepares handouts and students worksheets based on relevant references. The enrichment material of paramagnetic heat engine is developed by analyses of two basic competences previously explained. In connection to the ideal gas Carnot engine, we propose some critical questions: "Why does it use the ideal gas? Can it be others? What substances can alternate the ideal gas to create a Carnot engine?"

Some recommended references state that there are some thermodynamics systems that meet the laws of thermodynamics and are similar to the thermodynamics of ideal gas, of which are: stretched wire, surfaces, electrolytic cells, dielectric cells, and paramagnetic solid substance [8]. The physical quantities of the systems have analogies to those of ideal gas. The topic of paramagnetic substance was chosen since the scope of the material is comprehensive relating to topics of electricity and magnetism so that both will be used in higher grades. Table 2 compares the thermodynamics of ideal gas and paramagnetic substance.

So far a single reference describing a practical form of the paramagnetic heat engine and its applications for learning materials was not found. The intended assessment target is students with their creativity and reasoning are able in designing the paramagnetic heat engine using physical concepts that have been learned in the common teaching and learning activities. 
Table 2 Comparison between ideal gas and paramagnetic substance. [8]

\begin{tabular}{lcc}
\hline Physical Quantity & Ideal Gas & Paramagnetic Substance \\
\hline Generalized Force & $\begin{array}{c}P \\
\text { (pressure) }\end{array}$ & $\begin{array}{c}\mu_{0} H \\
\text { (Magnetic Intensity) }\end{array}$ \\
\hline $\begin{array}{l}\text { Generalized } \\
\text { Displacement }\end{array}$ & $\begin{array}{c}V \\
\text { (volume) }\end{array}$ & $\begin{array}{c}M \\
\text { (Total Magnetization) }\end{array}$ \\
\hline $\begin{array}{c}P V=n R T \\
\text { Equation of state }\end{array}$ & $\begin{array}{c}M=C_{C} H / T \\
\text { constant }\end{array}$ \\
\hline Work & $-P d V$ & $C_{\varepsilon}=$ Curie constant \\
\hline $\begin{array}{l}\text { First Law of } \\
\text { Thermodynamics }\end{array}$ & $d U=d Q-P d V$ & $d U=d Q+\mu_{0} H d M$ \\
\hline $\begin{array}{l}\text { Extensive Heat } \\
\text { Capacity }\end{array}$ & $C_{V}=(d U / d T)_{V}$ & $C_{M}=(d U / d T)_{M}$ \\
\hline $\begin{array}{l}\text { Intensive Heat } \\
\text { Capacity }\end{array}$ & $C_{P}=(d U / d T)_{P}+n R$ & $C_{H}=(d U / d T)_{H}+\left(\mu_{0} M^{2} / C_{c}\right)$ \\
\hline
\end{tabular}
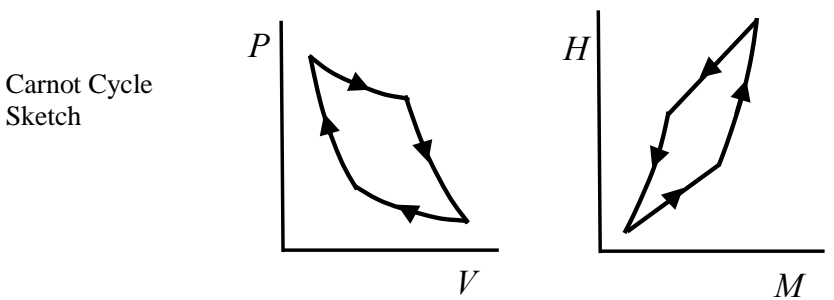

\section{Learners}

The learners' characteristics deal with students' background and prior knowledge. It is important for teacher to recognize them in designing the plan. The new topic requires certain prerequisites that students have to fill it. There are some ways that may be done by a teacher for checking the prior knowledge. They can be obtained through tests, classroom discussion, teacher's portfolios, or observation to students during instruction [17]. A common physics teacher has individual ways to obtain this preparation.

Observing learning analysis previously described one might question about the prior knowledge in absorbing the material. A lay reader regards that the contents of enrichment material need reliable mathematical reasoning and enough fundamental concepts about thermodynamics. Indeed, these are true. The material is logically delivered to students that have passed the analysis level of Bloom's taxonomy [18]. Some prerequisites including the ideal gas Carnot engine are well mastered before stepping to the enrichment material- A teacher does not need to force him/herself to deliver the enrichment material when the minimal objective is not obtained yet.

In other words, the enrichment material is known effective for students categorized as gifted and talented students who are with prominent academic potential or high score achiever students $[19,20]$. Gifted and talented students are known to be accustomed to: learn at faster rates; find, solve and act on problems more readily; and manipulate abstract ideas and make connections to an advanced degree [21].

\section{Learning Strategy}

A guided discovery process is often associated with laboratory activities, manipulating variables to obtain data, and making scientific report. It might be true [4]. However, the proper activities are based on the learned material. Students' activities in deriving mathematical formulas and designing tools from mastered concepts can also be categorized as guided discoveries [4]. During the enrichment material, students are not brought to a laboratory to conduct such experiments, but to explore physical concepts from references, group discussion, and presentation. In general, the guided discovery learning can be divided into five stages: introduction, problem statement, concept exploration, concept explanation, concept expansion, and closure [22,23].

In the introduction stage, a teacher reviews the students' prior knowledge. Conceptual questions are given to proving that students have mastered the topic of the Carnot engine employing ideal gas. It is also important for a teacher to underline that the Carnot engine employs a cycle consisting of two isothermal and two adiabatic processes. Then, a teacher informs students that the Carnot engine, which is known in the popular form (up and down piston moved by a gas) and its cycle, can apparently be created by employing other substances, such as paramagnetic substances. Moreover, a teacher should also introduce briefly the paramagnetic substances because the substances are a new learning material.

In the problem statement stage, a teacher drives students toward some questions: Why does the Carnot engine employ paramagnetic substances? What are the physical quantities of paramagnetic substances that are analogous with those of ideal gas? After the quantities were identified, how are the mathematical formulations? How is the form of the engine? The questions may be delivered when explaining the learning objectives or by putting in handouts and students' worksheets. Students are divided into several groups that have the capability to evenly. The grouping is prepared by observing the students' profile of the previous sessions in order to create effective social interactions among the group members.

In the concept exploration stage, students in each group begin working by reading handouts and doing students' worksheets. Students are freed to access relevant references from internet. If necessary, a teacher can give some guidance as needed to direct students in deriving the formula. In this stage, the theory of constructivism plays main role [23]. In connection with time allocation, the duration is two class meetings, in which each class meeting needs 2 x45 minutes. Students' activity does not normally finish at the concept exploration stage in the first meeting. It can be finished by giving homework in group. However, guidance outside the classroom can also be offered.

In the concept explanation stage, students report their results by giving presentation or answering teacher's questions in group. Students' works are verified and feedbacks are given for all achievements that were obtained. It is suggested not to blame students if they did wrong in deriving formulations, but let them know which steps are wrong. Students need to review the formulations so that they do not to repeat the same mistakes. Finally, students can make conclusions about the analogy of ideal gas and paramagnetic substances that meets the laws of thermodynamics under the teacher's guidance.

In the concept expansion stage, students present the design of a paramagnetic heat engine based on the concepts 
that have been learned in the previous stage. A teacher appreciates and gives comments on every design that was proposed. In the stage, synthesis and evaluation cognitive levels are reached by students.

In the closure stage, students make complete conclusions about activities that have been done. They can also give appreciation and comments for future better learning processes.

\section{Assessment}

As explained before, the enrichment material is delivered with a target to enhance the quality of students' thinking skill. It is important to assess students' group activities in each stage. The aspects developed in the learning process are reasoning and creative thinking skills. Therefore, a teacher should prepare assessment rubrics regarding to the competences that will be evaluated.

Assessment rubrics for the reasoning skill relate to how students make comparison among variables and obtain the relations, give logical arguments for their answers, develop divergent or convergent thinking abilities, solve problems, and make conclusions [24]. The reasoning skill is built by processes of finding analogy between ideal gas and paramagnetic substances in a heat engine. It can be observed from the performance in presentation and answering teacher's questions. While assessment rubrics for the creative thinking skill link to how students combine the learned concepts, personal ideas, imagination to create something unique and different. The creative thinking skill is assessed from the design of heat engine created in group [25].

\section{Conclusion}

A design on how a paramagnetic heat engine is taught by the guided discovery learning approach has been described. The stages were as follows: (1) Students begin the lesson by asking questions about other applications of the Carnot cycle that are not explained in the textbook; (2) A teacher gives clues that a heat engine can be created by employing a paramagnetic material; (3) Students investigate what quantities that enable paramagnetic substances can be used as a material for a heat engine; (4) Under the guidance of a teacher, students derive mathematical equations for designing paramagnetic heat engine; and (5) Students make conclusions and generalizations about activities that have been done. In addition, in each stage, an assessment is wrapped-up by the teacher to evaluate the students' reasoning and creativity to gain understanding in a meaningful and constructive manner.

\section{References}

[1] A. G. Balim, "The effects of discovery learning on students' success and inquiry learning skills," Eurasian J. Educ. Res., vol. 9, no. 35, pp.1, April 2009.

[2] M. R. Matthews, "Constructivism and science education: A further appraisal,” J. Sci. Technol., vol. 11, no. 2, pp. 121-134, 2002.

[3] J. A. Castronova, "Discovery learning for the 21 st century: What is it and how does it compare to traditional learning in effectiveness in the 21st century?" 2001. [Retrieved June 8, 2014], Web site: http://chiron.valdosta.edu/are/Litreviews/vol1no1/castronova_litr.pdf

[4] L. Alfieri, P. Brooks, N. Aldrich, and H. Tenenbaum, "Does discovery-based instruction enhance learning?" J. Educ. Psychol., vol. 103, no. 1, pp. 1-18, 2011.
[5] S. E. Cooperstein, and E. Kocevar-Weidinger, "Beyond active learning: A constructivist approach to learning," $R S R$, vol. 32 , no. 2 , pp. 141-148, 2004.

[6] http://www.gtvoice.org.uk/sites/www.gtvoice.org.uk/files/ 8enrichment.pdf [Retrieved June 26, 2014]

[7] http://www.gtvoice.org.uk/sites/www.gtvoice.org.uk/files/ 8enrichmentpr.pdf [Retrieved June 26, 2014]

[8] M. W. Zemansky and R. H. Dittman, Heat and Thermodynamics, $7^{\text {th }}$ ed., Singapore: McGraw Hill, 1997.

[9] R. Koper, "Current research in learning design," J. Educ. Tech. Soc, vol. 9. no. 1, pp. 13-22, 2006.

[10] http://www.slideshare.net/pmundin/r-what-is-learning-design [Retrieved June 26, 2014]

[11] http://ideaedu.org/sites/default/files/Idea_Paper_42.pdf [Retrieved June 26, 2014]

[12] A. Asgari, "Intended learning outcomes \& planned learning experience for technically developed curriculum," Int. J. Lang. Lit., April 2010.

[13] http://www.gifted.uconn.edu/siegle/curriculumcompacting/ 8steps.html [Retrieved June 26, 2014]

[14] Indonesian Ministry of Education and Culture. Kurikulum 2013: Kompetensi Dasar SMA/MA, 2003.

[15] J. Van Tassel - Baska, and T. Stambaugh, "Challenges and possibilities for serving gifted learners in the regular classroom, " $T I P$, vol.44, no. 3, pp. 211-217, 2005.

[16] C. Munzenmaier, and N. Rubin, "Perspectives Bloom's taxonomy: What's old is new again," The eLearning Guild, Santa Rosa, CA, USA,; $; 2013$.

[17] N. Strangman, and T. Hall, "Background knowledge." NCAC, U.S. Department of Education, 2010. Web. 14 July 2014.

[18] Direktorat Pembinaan SMA, Juknis Pembelajaran Tuntas, Remedial, dan Pengayaan di SMA, 2010. https://www.academia.edu/4657378/JUKNIS PEMBELAJARAN T UNTAs [Retrieved July 7, 2014]

[19] M. Reid, "Teaching implications of gifted and talented learners within the mainstream classroom," J. Stud. Engagem.: Educ. Matters (JSEEM), vol. 1, no. 1, pp. 29-32, 2011.

[20] New South Wales. Dept. of Education and Training. Curriculum K-12 Directorate. Policy and implementation strategies for the education of gifted and talented students / New South Wales Department of Education and Training Dept. of Education and Training, Curriculum K-12 Directorate [Sydney] 2004

[21] A. Akinbobola, and F. Afolabi, "Constructivist practices through guided discovery approach: The effect on students' cognitive achievements in Nigerian senior secondary school physics," Bulg. $J$. Sci. Educ. Policy, vol. 3, no. 2, pp. 233-252, 2009.

[22] J. M. Applefield, H. Huber, and M. Moallem, "Constructivism in theory and practice: Toward a better understanding," The High Sch. J., vol. 84, no. 2, pp. 35-53, 2001.

[23] B. Timmerman, et al, "Development of a 'universal' rubric for assessing undergraduates' scientific reasoning skills using scientific writing," Asses. \& Eval. in High. Educ., vol. 36, no. 5, 2011.

[24] https://www2.canyons.edu/Committees/SLO/Documents/Select\%20V alue\%20Rubrics.pdf [Retrieved July 7, 2014] 